\title{
Research on present situation of pre-hospital first-aid knowledge of the elderly in community in Jilin
}

\author{
Wenjing Sun, Yujin Liu ${ }^{a}$, Guixiu Yan, Wei Meng and Fengge Dong \\ Welfare College of Nursing of College of Humanities\&Northeast Normal University, 130117, Changchun, China
}

\begin{abstract}
Objective: This paper aims at understanding the present situation of pre-hospital first-aid knowledge of the elderly in community, which put forward good suggestions for developing the popularity of first-aid knowledge and training in Jilin. Method: Use convenience sampling method to select 200 elderly in community in Jilin, it makes questionnaire survey of first-aid knowledge and awareness. Result:The popularizing rate of first-aid knowledge of the elderly in community is quite low. There are obvious differences among people of different culture. Conclusion: It is urgent to develop popularity and training of first-aid knowledge to the elderly in community, so as to improve first-aid level of the elderly.
\end{abstract}

\section{Introduction}

Pre-hospital first-aid refers to on-the-spot rescue, transshipment and underway rescue of the injured who suffer all kinds of life-threatening emergencies, trauma and poisoning in the environment out of hospital. Although pre-hospital first-aid is temporary and meets for emergencies, effective pre-hospital first-aid can win valuable rescue time for saving the patient's life[1]. With the modernization of social life, the incidence of all traumas has been increasing year by year. As the elderly population at high risk of cardiovascular chronic diseases, first aid and mutual aid to master skills is particularly important. Pre-hospital care to grasp the precious lives of gold five minutes, can reduce the mortality of Emergency. To enable the elderly to better serve the community, but also serve their own[2]. Therefore, first-aid knowledge and awareness of peasants have directly connected with treatment and life security of the injured. In order to understand current situation of the elderly first-aid knowledge in community, the author made a questionnaire about related knowledge of the elderly in community in Jilin from Feb. to June, 2016. The report is as follows.

\section{Object and method}

\subsection{Object}

Use convenience sampling method to select Fengman district, Chuanying district, Changyi district, to

${ }^{a}$ Corresponding author: Liu Yujin,E-mail:1257819211@qq.com

This work was supported by a project grant from soft science of Health planning topics of Jilin

Province (2014R29). 
choose 200 elder people from community as research subjects. The age is range from 60 to 94 , the average age is 72 . Educational level: illiteracy 24, elementary school 57, middle school 68, high school(technical secondary school) 39, junior college and above 12. Of which, 121 males and 79 females. All team members are well-informed and willing to cooperate with the investigation.

\subsection{Investigation Method}

According to actual situations of China's the elderly in community, the questionnaire is self-designed and recognized by expert's evaluation. It contains general information(age, educational level, gender), mastering situation of first-aid knowledge, first-aid emergency measures and demand conditions. 20 students of Nursing Specialty from our university were chosen to be investigators after training. Questionnaires were filled in and taken back on the spot by investigators. 205 questionnaires were issued, 200 validated questionnaires were taken back and the valid return rate was $97.5 \%$.

\subsection{Statistical Method}

It adopts SPSS17.0 software to make a statistical treatment and applies $X^{2}$ test, the test level of alpha $=0.05$.

\section{Result}

\subsection{The elderly Understanding Conditions of Pre-hospital First-aid Knowledge}

It applies the popularizing rate of first-aid knowledge to evaluate the elderly understanding conditions of pre-hospital first-aid knowledge (Table 1) Popularizing rate= population of correct answers for one problem/ overall population answering problems[3].

Table 1. The elderly Understanding Conditions of First-aid Knowledge in Surveyed Areas $(n=200)$

\begin{tabular}{|c|c|c|}
\hline Content & $\begin{array}{l}\text { Population with Right } \\
\text { Answers }\end{array}$ & $\begin{array}{l}\text { Percentage } \\
(\%)\end{array}$ \\
\hline 1.Way to judge heartbeat and respiratory arrest & 63 & 31.7 \\
\hline 2.Places pressed while doing CPR & 15 & 7.3 \\
\hline 3.The proportion of pressing to blow while doing CPR & 5 & 2.7 \\
\hline 4.On-site rescue method for electric shock & 63 & 31.3 \\
\hline 5.How to rescue a drowning man & 70 & 35.0 \\
\hline 6.How to rescue the gas-poisoning injured & 75 & 37.7 \\
\hline $\begin{array}{l}\text { 7.On-site first aid for massive hemorrhage after artery } \\
\text { injury }\end{array}$ & 18 & 9.0 \\
\hline 8.How to move a patient with spinal injury & 11 & 5.7 \\
\hline 9.Emergence & 115 & 57.3 \\
\hline
\end{tabular}

As seen in Table 1, emergence call has the highest popularizing rate of first-aid knowledge(57.3\%), and the second one is the on-site rescue of poisoning injured(37.7\%). Places pressed of CPR(7.3\%), proportion of pressing to blow(2.7\%) and how to remove a patient with spinal injury $(5.7 \%)$ have quite low popularizing rates.

\subsection{Mastering Conditions of First-aid Knowledge of the elderly Belonging to Different Categories}

It applies the mastering rate of first-aid knowledge to evaluate mastering conditions of first-aid knowledge of the elderly belonging to different categories(anyone who can answer 8 problems or more in Table 1 master the first-aid knowledge[4] ), result is shown in Table 2. 
Table 2. Mastering Conditions of First-aid Knowledge of the elderly Belonging to Different Categories in Investigated Area $(\mathrm{n}=200)$

\begin{tabular}{|c|c|c|c|}
\hline \multicolumn{2}{|c|}{ Item } & Population & Mastering Rate(\%) \\
\hline \multirow{3}{*}{$\begin{array}{c}\text { Age } \\
\text { (year) }\end{array}$} & $60-69$ & 82 & $53(43.1)^{*}$ \\
\cline { 2 - 4 } & $70-79$ & 72 & $35(32.4)$ \\
\cline { 2 - 4 } & $80-94$ & 46 & $11(15.9)$ \\
\hline \multirow{3}{*}{ Educational Level } & Low( illiteracy, elementary school) & 71 & $31(25.4)$ \\
\cline { 2 - 4 } & Middle( middle school) & 68 & $33(32.4)$ \\
\cline { 2 - 4 } & $\begin{array}{c}\text { High( high school, technical secondary } \\
\text { school, university) }\end{array}$ & 51 & $34(44.7)^{* *}$ \\
\hline \multirow{2}{*}{ Gender } & Male & 121 & $65(35.7)$ \\
\cline { 2 - 4 } & Female & 79 & $41(34.7)$ \\
\hline$* P<0.05 \quad * * P<0.05$ & & & \\
\hline
\end{tabular}

As seen in Table 2, the age group with highest awareness rate(43.1\%) is $60-69$ years old. The lowest age group $(15.9 \%)$ is $80-94$ years old. With higher educational level, the awareness rate is higher. Differences are statistically significant $(\mathrm{P}<0.05)$,gender comparison has no statistical significance $(\mathrm{P}>0.05)$.

\subsection{The elderly Emergency Measures for Pre-hospital First-aid and Demand Conditions of First Aid}

Targeted at the problem of "If sudden death happens to somebody around you, what shall you do?", people are required to answer it openly on the spot. 35.3\% old people choose to ask people around them for help, $40.4 \%$ choose to call 120 emergency call, $13.4 \%$ do not know how to handle it, 3.4\% choose to go away and $7.5 \%$ choose the on-the-spot first-aid. As demand conditions of first aid, investigation shows that, $92.6 \%$ think that first-aid knowledge education should be developed, among which, $21.0 \%$ consider that first-aid knowledge education should start from the elementary school; $43.2 \%$ consider that this education should regularly be developed in communities.

\section{Discussion}

According to the survey, most of the aged are familiar with how to call for help. It shows that emergency call has been widely publicized in community, but on-the-spot rescue ability for all kinds of incidents is still weak. For instance, the accuracy of "proportion of pressing to blowing while doing CPR" is only $2.7 \%$, that of "how to move a patient with spinal injury" is only $5.7 \%$.Timely and effective CPR and correct moving method have great significance for saving the patient's life and preventing further injury. Investigations reveal that, the population of high educational level have quite high awareness rate of first-aid knowledge, which maybe relate to their long time for receiving education and wide channels to receive information. However, ill-educated old people have low awareness of first-aid knowledge and poor self-rescue ability. It is possible that weak educational degree limits their mastering and understanding of first-aid knowledge[5].

During the investigation, the problem of "If sudden death happens to somebody around you, what shall you do?" was put forward to respondents. 13.4 old people did not know how to deal with it, $3.7 \%$ chose to go way who were afraid of getting into trouble and only $7.5 \%$ chose to make on-site first aid. All these show that, on one hand, cultural knowledge has already become the obstacles for pre-hospital first-aid knowledge to be popularized and developed in community; on the other hand, it shows that ideological and ethical standards of the aged need to be improved. According to this investigation, $69.6 \%$ peasants are quite willing to master first-aid knowledge. It can be seen that the 
aged have a quite low comprehensive first-aid ability. However, due to objective reasons of economic conditions and geographical locations, access and timeliness of professional medical emergency rescue are far away from that of cities, therefore, these groups have more urgently objective demands for first-aid knowledge and skills. It is suggested that governments and related departments should take full advantage of broadcast, TV and newspapers $\&$ periodicals to make publication and education of importance of first-aid knowledge, regularly assign organizations and personnel with training qualities to go deep into the countryside, apply more methods to regularly develop training and practicing of first-aid skills, such as simulating first-aid spot, multimedia cases and role play, so as to improve first-aid skills and awareness of the aged[6].

\section{Conclusion}

Through this pre-hospital First-aid Knowledge for the elderly in community surveys, found that elderly people who living alone, community health is not in place, the lack of pre-hospital emergency care knowledge etc. affect the ability of pre-hospital community of the elderly. We can update the concept, to strengthen pre-hospital care community strength, improve the quality of pre-hospital care community and other methods to improve and enhance the ability of emergency care homes for the elderly before the community, improving the quality of life of older people.

\section{References}

1. Yang Aizhen, Xu Jinggang, Song Peiqiu, Tao Xiangling. Pre-hospital emergency care for the elderly Discussion in community. Journal of Nursing Science,11,4(1996).

2. Yao Hongying. Comprehensive intervention for the elderly to master first aid skills Evaluation. Zhe Jiang University(2012).

3. Zhang Aiwu. 378 cases of the elderly in community pre-hospital emergency care analysis. Foreign Medical Treatment,10,24(2009).

4. Wang Hong, Zhu Lirong, Zhang Xuefeng, Zhu Dingfa, Zhang Lu. Residents first aid knowledge, attitude, behavior Status Survey.China Medical Herald,9,6(2012).

5. Huang Wenjie. 629 cases of pre-hospital emergency care in elderly community survey.Modern Medicine, 16,14(2007).

6. Hu Suzhen. Establishment and implementation of community self-help and mutual aid system. Fu Dan University(2012). 